\title{
NOVAS INSTITUIÇÕES E PROCESSOS EDUCATIVOS: A EDUCAÇÃO E O MODỎ DE REGULAÇÃO EM GESTAÇÃO. UM ESTUDO DE CASO EM PORTUGAL
}

\author{
FÁtima Antunes*
}

RESUMO: No terreno da educação (e das políticas sociais em geral) algumas mudanças das últimas décadas traduzem-se quer por uma redefinição dos serviços educativos (e de bem-estar) e do papel do Estado na sua governação, quer pela emergência de novas configuraçôes da participação da educação na regulação social. Um estudo de caso, incidente sobre o subsistema de escolas profissionais criado em 1989 em Portugal, permite sinalizar algumas dessas alterações recentes e propor interpretaçóes acerca do seu significado. A análise do lançamento daquela modalidade de escolarização de nível secundário, de algumas das suas evoluçōes e de orientações e práticas desenvolvidas em duas escolas profissionais sugere que aquela inovação testemunha o ensaio de novas instituiçõos e processos educativos envolvidos com a gestação de um outro modo de regulação - distinto daquele que foi definido como fordista e em que teve lugar o desenvolvimento do(s) modelo(s) de Estado de Bem-Estar.

Palavras-chave: Educação e regulação social. Globalização, europeização e políticas educativas. Formas de actuação do Estado e políticas educativas. Transição profissional.

NEW EDUCATIONAL INSTITUTIONS AND PROCESSES: EDUCATION AND THE NEW REGULATION MODE IN PREPARATION.

A Case STUdy IN Portugal

ABSTRACT: These last decades, in the field of education (and of social policies in general), some changes resulted both in a redefinition of the educational (and welfare) services and of the role of the governance of the State and in the emergence of new configurations for the participation of education in the social regulation. A case

Professora do Instituto de Educação e Psicologia da Universidade do Minho (Portugal). E-mail: fantunes@iep.uminho.pt 
Novas instituições e processos educativos: a educação e o modo...

study on the vocational school subsystem created in 1989 in Portugal allows us to identify some of these recent alterations and to propose some interpretations about their meaning. The analysis of the launching of such a schooling modality and of some of the orientations and practices developed in two vocational schools suggests that this innovation testifies the experimentation of new educational institutions and processes related with the formation of a new regulation mode - distinct from that defined as Fordist in which the development of the Welfare State model(s) occurred.

Key words: Education and social regulation. Globalization, Europeification, and education policies. State action forms and education policies. Professional transition.

\section{Introdução}

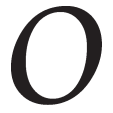

complexo de dinâmicas, instituições, processos e relaçóes sociais que alguns de nós, na senda de Wallerstein (1990, 1991, 1995), procuraram compreender mobilizando o conceito de moderno sistema-mundo capitalista sofre, desde há algumas décadas, transformaçóes dramáticas que têm vindo a ser teorizadas como configurando processos de globalização. Essas mudanças são, por alguns autores, referidas como globalizaçôes, para sublinhar a heterogeneidade, as assimetrias, contradiçôes e os desequilíbrios que marcam as constelaçôes de relações sociais que as corporizam (cf., por exemplo, Santos, 2001a); as dinâmicas que enunciamos são hoje vividas na economia, na esfera política ou no universo cultural por meio de uma combinatória de processos cuja instabilidade não permite ainda apreender qualquer configuração identificável como constituindo um novo regime de acumulação. ${ }^{1}$

Uma das mudanças contemporâneas mais salientes, no domínio das relações económicas e políticas, é a emergência de um novo protagonismo por parte de blocos e entidades de carácter regional associada a uma crescente importância assumida por instituições internacionais com uma existência mais ou menos duradoura. ${ }^{2}$ As organizações regionais têm sido analisadas como entidades supranacionais fundadas com base em acordos multilaterais entre Estados e cuja actuação simultaneamente medeia e contribui fortemente para o desenvolvimento de dinâmicas de globalização e dos seus efeitos; constituem, assim, instâncias que criam, modelam, filtram e veiculam esses processos (cf. Dale \& Robertson, 2000). 
A União Europeia representa uma das formas institucionais mais avançadas neste domínio, desenvolvendo um vasto âmbito de intervenção e assumindo progressivamente um papel mais activo (em sentidos divergentes e com resultados diversificados) na área das políticas sociais. Não pode deixar de ser salientada a associação estreita entre as dinâmicas que referimos e a emergência de novas formas de actuação do Estado com impacto decisivo nessa área de acção; neste sentido, assume relevo essencial a análise das relações entre o denominado processo de integração europeia e a elaboração das políticas educativas nacionais, estudo que desenvolvemos com algum detalhe em outros trabalhos. Aí argumentamos que o processo de europeização e de constituição de um referencial global europeu para as políticas educativas nacionais está em curso há já algumas décadas (cf. Nóvoa, 1998) ${ }^{3}$ e de uma forma mais expressiva a partir de meados dos anos de 1980, verificando fases e modalidades distintas que procurámos também analisar. Podemos, assim, identificar, nomeadamente no período compreendido entre 1986 e 1992, o que consideraríamos como três modalidades de produção de processos de europeização das políticas educativas nacionais:

(i) a definição de agendas e prioridades comuns aos Estadosmembros, na esfera da educação;

(ii) o estabelecimento de uma agenda e de uma política comunitárias para a educação;

(iii) a recontextualização de políticas comunitárias (cf. Antunes, 2001, 2003b).

Neste texto, vamos centrar a atenção em outras dimensões da configuração de um novo modo de regulação $0^{4}$ estreitamente relacionadas com aqueles fenómenos, mas analítica e empiricamente distintos.

$\mathrm{Na}$ senda de diversos autores temos procurado apreender e condensar os complexos de relações sociais que corporizam reestruturaçōes emergentes dos papéis do Estado por meio das noçôes de Estado de competição, Estado-em-rede e Estado-articulador, as quais, embora de modo imperfeito e insatisfatório, pretendem dar conta de formas específicas de acção estatal que podem surgir singularizadas ou combinadas em determinadas áreas da vida social. O Estado parece assim envolvido em transformações que apontam para três configurações ou formas de actuação parciais fundamentais: o Estado de competição (competition 
Novas instituições e processos educativos: a educação e o modo...

State) cujas prioridades se orientam para a actuação em instâncias supranacionais e para a intervenção no nível nacional com o fim de promover a competitividade da sua economia e de expandir as oportunidades de acumulação (cf. Cerny, 1990, p. 53, 205, 220 e ss.); o Estadoem-rede (the network State) como articulação de segmentos de Estados que asseguram a intervenção em áreas da vida social cujo controlo escapa às fronteiras da soberania nacional (cf. Castells, 1997, p. 266-269; 1998, p. 331, 350-352, 366-367, 375); e o Estado-articulador voltado para a criação de condições de mediação dos interesses sociais, sob novas fórmulas e arranjos institucionais de que não é o único nem o principal protagonista (cf. Santos, 1998, p. 59-69; 1999, p. 38-39). Defendemos que, por meio dessas formas de actuação, o(s) Estado(s) te(ê $) \mathrm{m}$ vindo a reforçar o seu protagonismo como actor(es) central(is) na gestação de novas formas de regulação social. Desse modo, a emergência de um novo modo de regulação, que assume uma forma concreta também no nível nacional, cristaliza os efeitos mais importantes dos processos de globalização (cf. Dale, 2000a e 2000b). ${ }^{5}$

No terreno da educação (e das políticas sociais em geral) estas mudanças, que conformam uma agenda globalmente estruturada, ${ }^{6}$ traduzem-se quer por uma redefinição dos serviços educativos (e de bemestar) e do papel do Estado na sua governação, quer pela emergência de novas configurações da participação da educação na regulação social.

Entre nós, alguns autores, propondo análises com um foco importante na educação, enunciaram, ainda que no contexto de problemáticas distintas e, portanto, por meio de uma outra linguagem, o desenvolvimento de constelações de processos que, tal como sugerimos neste estudo, apontam para a gestação deste novo modo de regulação. Assim, Esteves identifica a constituição de um regime de transiçâao ao trabalho, distinto daquele que vigorara na maior parte dos países europeus e ocidentais até meados da década de 1970, que "corresponde a uma tensão contraditória nos sistemas sociais da escola e do emprego, até ao ponto de se transformar num problema social básico e num campo de intensiva intervenção do Estado". Esse autor sublinha ainda um complexo de mudanças sociais associadas com aqueles fenómenos afirmando que

o conceito de transição ao trabalho é, relativamente às categorias juvenis, uma metáfora de múltiplas referências, através da qual se configuram lógicas e processos sociais de outro modo dificilmente reconhecíveis, envolvendo en- 
tidades sociais - escola, família, jovens, saberes, Estado, gerações - que já não

(a)parecem como pareciam. (Esteves, 1994, p. 87, 91, grifos do autor)

Partindo de preocupações diversas, Stoer propõe a consideração de duas "formas de relação do Estado com a educação escolar" que apontam para distintas relaçóes entre Estado e economia e entre escola e mundo do trabalho identificáveis ao longo do século XX. Assim, o autor considera uma primeira forma de relação do Estado com a educação escolar que designa por meio da expressão "estrutura ocupacional e democratização social", característica das sociedades em que o regime de acumulação fordista e o modelo de Estado de Bem-Estar se desenvolveram com algum significado; em contrapartida, argumenta, a

segunda forma da relação entre o Estado e a educação escolar fermenta nas preocupações relacionadas com a 'criação de oportunidades de emprego e promoção da retomada do crescimento económico’ (...) a escola para todos desarticula-se com um sistema produtivo que desenvolve o desemprego estrutural (...) [e] o Estado assume-se plenamente como Estado-regulador, como mediador de um novo processo de concertação social que passa pela preocupação de garantir, em primeiro lugar, a competitividade do país em face de um mercado cada vez mais mundializado. (Stoer, 2001, p. 247, $252,257-258)$

$\mathrm{Na}$ análise a seguir desenvolvida procuraremos sustentar teórica e empiricamente o argumento de que testemunhamos o desenvolvimento de constelaçóes de mudanças e processos sociais, em que se incluem aqueles identificados pelos autores citados, que, no campo da educação, configuram novas instituições e processos educativos envolvidos com a gestação de um outro modo de regulação que implica a participação da educação segundo modalidades inéditas.

\section{A criação do subsistema de escolas profissionais em Portugal}

\subsection{Uma breve contextualização}

Um estudo de caso incidente sobre o subsistema de escolas profissionais criado em Portugal em 1989 permite sinalizar algumas dessas alteraçôes e propor interpretaçôes acerca do seu significado. A análise dessa inovação torna possível enunciar alguns vectores do que designamos como a agenda política nacional para a educação elaborada 
Novas instituições e processos educativos: a educação e o modo...

e promulgada num período que entendemos compreendido entre 1988 e 1993. Argumentamos que este conjunto de problemas, soluções e expectativas é estruturado por processos globais cujas recepção e interpretação são específicas num dado contexto nacional. A reacção àquelas dinâmicas depende, assim, quer dos constrangimentos, quer dos recursos sócio-institucionais que, numa dada conjuntura, afirmam-se como efectivamente actuantes. A crise e consolidação do Estado de Bem-estar e da escola de massas (cf. Santos, 1990; Stoer \& Araújo, 1992), o processo de Reforma do Sistema Educativo, levado a cabo por meio de um conjunto de medidas de política educativa integrantes da orientação de neoliberalismo educacional mitigado que marcou a acção governativa na época em questão (cf. Afonso, 1998), constituem dinâmicas sócio-políticas que definem o contexto em que têm lugar os processos que analisamos.

O sistema educativo português apresenta-se, no final dos anos de 1980, como um serviço público com marcadas características de subdesenvolvimento, dados os níveis de cobertura da população que é capaz de proporcionar, quer dos pontos de vista quantitativo (taxa de freqüência) como qualitativo (taxa de sucesso nas aprendizagens e de distribuição de diplomas). O diagnóstico elaborado pela administração central, como base da proposta à União Europeia (então Comunidade Económica Europeia) do Programa de Desenvolvimento Educativo para Portugal (1990-1993) (PRODEP I), é, a esse título, elucidativo: "A taxa de escolarização da população portuguesa no primeiro nível (90\%) é comparável com a dos outros países, mas a do segundo nível já é cerca de metade da média dos outros membros da comunidade e a do terceiro nível ou do ensino superior é ainda menos de metade da média desses países" (com base em dados de 1987). Assim, em 1987/1988, verificam-se as seguintes taxas de escolarização: educação pré-escolar, $30 \%$; ensino básico ( $1^{\circ}$ ciclo, $100 \%$; $2^{\circ}$ ciclo, 90\%); ensino secundário, 40\%; ensino superior, 11\% (cf. Gabinete de Estudos e Planeamento/Ministério de Educação, 1990, p. 28, 37).?

\subsection{As novas formas de actuação do Estado e a expansão dos serviços educativos}

A fundação do subsistema de escolas profissionais em Portugal participa de um processo longo de cerca de uma década em que tive- 
ram lugar diversas tentativas de reestruturação da oferta de ensino/ formação de nível secundário. Assim, num primeiro momento, entre 1980 e 1989, assistimos a inovações que vão no sentido da diferenciação de vias no seio de uma mesma instituição, a escola secundária, na senda de modelos tradicionalmente adoptados nesse nível de ensino. A partir de finais da década de 1980 , e no momento que especificamente estudamos, é a expansão com segmentação da escola de massas e a generalização, com dualização, do ensino/formação de nível secundário que estão em curso. Nesse período, as medidas adoptadas vão no sentido da diversificação das modalidades de provisão dos serviços educativos. Estas são marcadas por clivagens de natureza institucional que se prolongam segundo linhas de hierarquização desses bens e serviços e pela estratificação dos seus beneficiários. ${ }^{8}$

A criação do subsistema de escolas profissionais em 1989 é promovida no contexto da Reforma do Sistema Educativo9 como uma modalidade alternativa de escolarização de nível secundário, essencialmente votada à aproximação dos jovens em face dos contextos de trabalho e das realidades produtivas. Pretende-se criar formaçôes terminais, de "espectro largo", local ou sectorialmente relevantes e integradas, proporcionando a qualificação de técnicos e trabalhadores polivalentes e favorecendo a empregabilidade dos jovens. Esta modalidade de ensino não-regular dá acesso a um diploma profissional de certificação de qualificação de nível III equivalente, para efeitos de prosseguimento de estudos, ao diploma do ensino secundário. A fundação e o desenvolvimento das escolas e dos cursos deveria assentar no envolvimento e na responsabilização de promotores, oriundos da sociedade civil, com um projecto de educação ligado ao desenvolvimento de regióes ou de sectores da economia, e capazes de, a prazo, prover à sustentação financeira das instituições por meio da captação de receitas de múltiplas fontes.

Uma ideia parece emergir com força suficiente para que possa ficar agora registada: a proximidade curricular entre os dois tipos de cursos de nível secundário proporcionados no sistema de ensino regular é estabelecida em simultâneo com a institucionalização de duas modalidades alternativas de acesso ao ensino/formação do mesmo nível, exteriores àquele, uma de carácter escolar, o subsistema de escolas profissionais, outra de natureza extra-escolar, os cursos de Aprendizagem, de nível III. Dirigidas as quatro modalidades à população 
Novas instituições e processos educativos: a educação e o modo...

saída da escolaridade obrigatória, tal segmentação corresponde à gestão e reestruturação do ensino/formação de nível secundário com o fim de gerar respostas a pressões e problemas distintos que se colocam em simultâneo mas podem apelar a soluçôes dificilmente compatibilizáveis senão contraditórias.

Em Portugal, as transformações globais que conduziram à forma de actuação como Estado de competição - cujas prioridades se orientam para a ampliação das oportunidades de acumulação, distanciando-se de todas as actividades que possam constituir uma ameaça a tal determinação, nomeadamente aquelas que sustentam a promoção do bem-estar social - convergiram com dinâmicas sócio-políticas que tornaram imperativa a expansão dos serviços educativos, exigida, disputada e submetida a pressões contraditórias por parte de distintos grupos e sectores sociais. ${ }^{10} \mathrm{O}$ subsistema de escolas profissionais, como inovação sócio-política particularmente ilustrativa neste domínio, caracteriza-se por essa duplicidade. Estava-se perante uma situação atravessada por dilemas e tensões cuja gestão foi tentada por meio de medidas que concorreram simultaneamente para a ampliação $e$ fragilização da cidadania educativa. A ampliação da cidadania é promovida porque o acesso a percursos de escolarização prolongada e à certificação de nível secundário é alargado por intermédio da criação do subsistema de escolas profissionais (e do Sistema de Aprendizagem, de nível III). A fragilização do usufruto desse direito por uma significativa parte da população decorre do carácter particularista (Dale, 2000a) daquelas políticas que, longe de concorrer para a generalização de um dado nível de bens e serviços de valor social e educativo equivalente, posicionam e estratificam os seus beneficiários. A fragilização da cidadania resulta ainda da segmentação institucional que corporizou a provisão de tais serviços e do carácter privado assumido pelo subsistema de escolas profissionais. Isso porque, neste caso, não só não é fornecido um serviço educativo com valor social equivalente como não é usufruído em condições de paridade com os beneficiários do ensino regular.

\subsubsection{Novas modalidades de provisão de serviços educativos}

As escolas profissionais constituíram uma inovação que entrou em ruptura com o modo como a educação escolar fora proporcionada 
em Portugal até ao momento de criação daquelas, no que toca a qualquer das actividades - financiamento, fornecimento e regulação -, cuja análise Roger Dale considera incontornável para compreender a governação ("governance") da educação (cf. Dale, 1994, p. 2-6; 1997). ${ }^{11}$ Assim, o seu financiamento é fundamentalmente público e estatal (incluindo aquele que provém dos Fundos Estruturais da União Europeia), contemplando também a participação das entidades promotoras e dos estudantes, por meio de propinas, entre outras modalidades; dessa forma, embora fortemente sustentado pelo Estado, apresenta ainda assim um carácter misto que não deve ser ignorado. Deve-se salientar que essa estrutura de financiamento, que se manteve durante cerca de uma década, deveria, segundo o projecto dos seus criadores políticos, ter progressivamente evoluído para a auto-sustentação das escolas por meio do investimento dos promotores e de receitas provenientes quer das propinas dos alunos, quer das empresas interessadas nas formações proporcionadas, quer aquelas geradas pelas próprias instituiçôes (cf. Azevedo, 1991, p. 156, 168; Alves, 1996, p. 38-41).

O fornecimento do serviço educativo foi assumido pelas escolas profissionais, instituiçôes dotadas de autonomia, com base num contrato-programa com o Estado que especificava responsabilidades, competências e âmbitos de actuação. As áreas da relação com os produtores (professores, formadores e funcionários) e beneficiários (alunos) do serviço foi, desse modo, deslocada para o nível da instituição local; no entanto, se o estatuto dos produtores e beneficiários releva duma relação individualizada, parcialmente mercadorizada (isto é, sujeita à capacidade e às condições de negociação da relação laboral para uns e, pese embora o carácter específico de que tal se reveste, de aquisição do serviço para outros), aquele é também fortemente determinado por normas oriundas dos poderes públicos (quer estatais, quer da União Europeia) relativas à prestação do serviço (perfil e qualificações dos formadores ou custo/valor atribuído ao tempo de formação...) bem como às características dos seus destinatários (qualificaçōes, faixa etária, entre outras).

A regulação do serviço educativo é protagonizada basicamente por duas entidades: a administração do sistema educativo e as escolas. ${ }^{12}$ A primeira entidade mencionada assume a definição das normas e dos critérios genéricos e essenciais relativos à oferta de cursos (que necessitam de aprovação prévia para poder funcionar), aos currí- 
Novas instituições e processos educativos: a educação e o modo...

culos e planos de estudos, à avaliação e à gestão das escolas. As próprias escolas (leia-se, os seus órgãos de direcção) concebem e propõem para aprovação os seus projectos de ensino, ficando a gestão curricular e pedagógica, financeira e administrativa como competências do seu foro próprio.

A agenda reformista corporizada pela criação do subsistema de escolas profissionais aparece como um exemplo emblemático de algumas das transformações sofridas pelo Estado de Bem-estar nas últimas décadas. $\mathrm{O}$ ensaio de novos arranjos institucionais contribuiu para diluir o carácter estatal e público da educação, redistribuindo responsabilidades na gestão da sua provisão e redefinindo o conjunto de actores e entidades que legitimamente participam na sua produção e os respectivos papéis no conjunto do processo. Os promotores, o contrato-programa e o partenariado foram os instrumentos que permitiram a edificação desta combinação institucional em que o financiamento, fornecimento e a regulação dos serviços prestados são coordenados segundo formas relevando do Estado, do Mercado e do Terceiro Sector. Consideramos, por isso, que esta iniciativa política configura uma forma de actuação como Estado-articulador favorável não só à emergência de outros actores e interesses sociais como à procura por novas regras para o seu confronto e mediação. Notoriamente, e numa iniciativa sem precedentes, o Estado dinamizou e envolveu-se activamente na criação de todo um subsistema de ensino que é, em regra, privado. A invenção de novas modalidades de provisão de serviços sociais - que permitissem redefinir campos de acção, protagonistas e responsabilidades, a natureza dos bens e serviços, do contrato social que os suporta e a relação preconizada com os seus beneficiários bem como o estatuto destes - foi o projecto lançado, e em boa medida concretizado, por intermédio desta medida de política educativa.

Assim, os problemas confrontados pelo Estado português - em que a prioridade à competitividade nacional e ao processo de acumulação se conjugou com pressões sociais contraditórias relacionadas com a expansão dos serviços educativos - criaram as condições para a gestação de uma inovação política em que se combinam, de modo específico, as formas de actuação como Estado de competição e como Estado-articulador e que exprime a forma concreta assumida no nosso país pela agenda globalmente estruturada para a educação. A modalidade de provisão de bem-estar assim estabelecida é marcada pela ten- 
dência para ampliar o domínio do privado como locus de promoção do bem comum; nesse processo é o próprio modelo de provisão de serviços educativos que é alterado. ${ }^{13}$ A dinâmica gerada é, no entanto, suficientemente heterogénea e ambivalente para sugerir que formas inovadoras de promoção da coesão com justiça social podem também ter sido experimentadas.

2. Novos processos educativos: a participação da educação na regulação social

A análise de orientações e práticas desenvolvidas em duas escolas profissionais, Valdéon e Tresviso, permitiu esclarecer e aprofundar algumas das tendências que, na actualidade, marcam a esfera educativa em Portugal ou surgem como realidades ainda singulares que podem ensaiar ou prenunciar desenvolvimentos futuros de mais vasto alcance. ${ }^{14}$

Uma primeira caracterização das escolas estudadas, com base em dados sobretudo estatísticos, revelou que a consideração da criação do subsistema de escolas profissionais como uma política selectiva (Dale \& Ozga, 1991, p. 26-27) sai confirmada, senão reforçada em sentidos paradoxais: a definição deste percurso de escolarização como modalidade alternativa ao ensino secundário regular, combinada com o acesso condicionado de que é alvo, produz o resultado de que são as escolas a seleccionar os alunos que as escolhem. Neste sentido, a expansão dos serviços educativos por meio de uma política selectiva cujo âmbito é, por sua vez, restringido tem um duplo efeito estratificante: não só posiciona os seus beneficiários como se revela uma falsa alternativa para muitos daqueles a quem alegadamente se destinaria, nomeadamente os que são excluídos em função do número de vagas. As condições que configuram o funcionamento deste subsistema revelam então uma política que fragiliza a cidadania educativa por meio de um outro fenómeno: a negação da igualdade de oportunidades de acesso a bens e serviços educativos. Pode argumentar-se que estes jovens excluídos continuam a poder candidatar-se e frequentar um dos três percursos restantes que proporcionam uma formação de nível secundário. Se tal é formalmente verdadeiro, de facto, não se verifica o efectivo direito a uma educação adequada às suas necessidades e às condiçôes de usufruto dos bens culturais. Isso porque os percursos regulares do ensino secundário não só permanecem exacerbadamente elitistas e selectivos 
Novas instituições e processos educativos: a educação e o modo...

como mantêm a referência central à matriz liceal de organização e desenvolvimento curricular. Por sua vez, os cursos de Aprendizagem constituem igualmente uma modalidade cujo acesso é restringido. É assim que a ampliação da cidadania educativa proporcionada pela criação deste subsistema se encontra severamente fragilizada, não só pelo carácter particularista da provisão de bens e serviços como pela restrição de acesso a estes. O carácter particularista da política que instituiu esta via de escolarização é confirmado pela natureza tendencialmente terminal que ela assume para os jovens que a concluem. Em claro contraste com os percursos do ensino secundário regular, as Escolas Profissionais Tresviso e Valdéon definem-se pelo facto de que os seus estudantes massivamente concluem nesse estádio a sua formação escolar, pelo menos como projecto subsequente à certificação alcançada.

O estudo de caso realizado nas Escolas Profissionais Valdéon e Tresviso permitiu analisar aquelas orientações e práticas de organização, transmissão e avaliação do conhecimento e de organização da escola referenciáveis ao mandato atribuído às escolas profissionais, identificado em torno de quatro vectores (cf. Antunes, 2003b): ${ }^{15}$

(i) a integração de públicos em colisão com o ensino regular;

(ii) a construção de (novas) identidades sociais e profissionais;

(iii) a qualificação de recursos humanos;

(iv) a gestão da inserção profissional dos jovens.

A articulação de tais vectores denota a presença significativa de preocupações que sugerimos serem associáveis à emergência de novas dimensões da participação da educação na regulação social.

Neste texto iremos apenas considerar o estudo realizado relativo aos processos educativos referenciáveis ao domínio da gestão da inserção profissional dos jovens.

\subsection{A organização da transição profissional: uma perspectiva de elucidação de novos fenómenos e processos sócio-políticos}

Surgindo como categoria construída no contexto de preocupações, discursos, opções e intervenções sociais e políticas, a inserção profissional dos jovens tem vindo a ser, desde há largos anos, objecto de estudos e debates que procuram contribuir para a explicitação, 
compreensão e explicação científico-sociais dos processos em acção nesse domínio.

Os trabalhos de José Rose constituem estudos de referência pioneiros e inovadores, sobretudo, pela proposta teórica que desenvolvem para a investigação daquela questão por meio da sua reformulação em termos de transição profissional e de elucidação dos modos de acesso aos empregos e dos processos que os organizam. Definindo como objecto de estudo "a análise do conjunto de intervenções que têm um papel directo sobre as condiçóes de acesso aos empregos", pretende-se, nesta perspectiva, apreender e sublinhar a sobreposição complexa de formação, actividade e inactividade que acompanha a progressiva autonomização, nas últimas décadas, do processo de inserção profissional crescentemente marcado pela multiplicação das formas sociais que asseguram a sua organização (Rose, 1984, p. 50-55; 1996, p. 64).

A análise da inserção profissional dos jovens, agora referenciada à problemática mais geral da transição profissional, surge, no momento actual, inscrita no contexto de políticas e práticas de diversos autores, em que avultam, entre outros, os agentes de transição (instituições que actuam no campo do emprego e da formação); os poderes públicos, cujas intervençôes edificaram uma tão complexa como pouco conhecida política de transição profissional; as empresas, cuja influência no modo de funcionamento do mercado de emprego dificilmente pode ser sobrevalorizada. As intervençóes de tais actores orientar-se-iam, ainda que registando ênfases diversas, para o duplo objectivo de alterar as "condições de aquisição da qualificação" e "de mobilização da força de trabalho" (cf. Rose, 1984, p. 183-184; Dupaquier et al., 1986, p. 81-82). Algumas das mais importantes mudanças quanto aos modos como é construída, mobilizada e reconhecida a qualificação dos trabalhadores são testemunhadas por: a imbricação entre momentos e lugares de formação e de exercício da qualificação, por meio do envolvimento das empresas e da constituição de modalidades diversas de alternância; o "duplo movimento de exteriorização/interiorização da formação" por parte das empresas, variável segundo as situações e os tipos de formação; a extensão do campo da qualificação para incluir explicita e obrigatoriamente dimensões técnicas, sociais, éticas e comportamentais (cf. Dupaquier et al., 1986, p. 81-82).

Em simultâneo, o estabelecimento de um dispositivo de transição - isto é, de uma diversidade de mecanismos institucionais que visam a alterar a preparação, e favorecer a mobilização e mobilidade, da força 
Novas instituições e processos educativos: a educação e o modo...

de trabalho, criando, controlando e regulando modalidades de passagem entre situações de formação, emprego e desemprego - facilita o recrutamento e a selecção de mão-de-obra, diminuindo os seus custos para as empresas, e contribui para naturalizar a precariedade e transitoriedade dos estatutos, dos vínculos e das situações de trabalho. O conjunto desses mecanismos constitui ainda uma forma de gerir e regular o nível de desemprego, de atenuar as consequências deste para os indivíduos bem como os seus custos sociais mais gravosos em termos de ordem e coesão social (cf. Rose, 1984, p. 145, 156-159, 173-177, 184-185; 1996; Dupaquier et al., 1986, p. 81-82; Calan, Carlier \& Vinokur, 1998, p. 61-74).

\subsection{As práticas de inserção profissional em escolas profissionais: um ensaio de interpretação}

A inserção profissional dos seus formandos coloca-se como uma das preocupações prioritárias dos responsáveis das escolas profissionais que estudámos. O nível alcançado na concretização de tal objectivo constitui, aliás, um dos índices reivindicados pelas instituições e evocado por políticos como testemunho do sucesso do subsistema, sendo também referido como uma condição importante para o financiamento público dos cursos.

As escolas desenvolvem, assim, um conjunto de orientações e práticas que visam a facilitar o acesso ao emprego por parte dos seus alunos; trata-se de assumir a gestão da inserção profissional combinando ou privilegiando um de dois tipos de actuação:

(i) articular os seus processos de colocação dos estudantes em experiências de trabalho e/ou emprego com processos de recrutamento de mão-de-obra por meio da constituição de uma teia apertada de relaçóes com empregadores locais;

(ii) incluir na formação conteúdos específicos correspondentes a saberes e habilidades imediatamente utilizáveis em processos produtivos de empresas locais.

2.2.1. Os limites da cooperação: entre a oferta de serviços e a busca de oportunidades

As práticas predominantes neste domínio nas escolas estudadas se orientam para o estabelecimento de ligações com entidades empre- 
gadoras susceptíveis de facilitar o acesso a um emprego para os seus formandos. Essas relações assumem formas distintas e assentam em múltiplos dispositivos em que sobressaem a organização de estágios curriculares (e também profissionais), o convite à participação nos júris das Provas de Aptidão Profissional dos alunos, a recepção e o encaminhamento mais ou menos formalizados e sistemáticos de ofertas e pedidos de emprego bem como outros processos mais difusos de promoção da formação desenvolvida pelas escolas junto de potenciais entidades empregadoras (organização de visitas, conferências e diversas modalidades de envolvimento de quadros e responsáveis por empresas e outras instituições em iniciativas desses estabelecimentos de ensino). Por meio de múltiplas formas diligencia-se criar algumas vias de acesso privilegiado a postos de trabalho disponíveis aos seus alunos.

Em relação ao terceiro ano o que tem havido é o seguinte: faz-se um levantamento dos alunos que pretendem seguir o ensino superior e os alunos que querem trabalhar, e depois fazemos um contacto com as empresas e privilegiamos as empresas que querem pessoas para trabalhar. Depois procuramos colocar, em função dos elementos que as empresas nos dão, "queremos um para esta área assim, assim, com estas características (...)" e procuramos conduzir e canalizar os alunos para aqueles locais onde à partida terão boas hipóteses de ficarem a trabalhar, e temos tido um nível de sucesso grande nesse aspecto. (...) E tem havido um bocado este diálogo, tem havido o alargamento da nossa colaboração com algumas empresas, nós temos empresas onde já temos para aí 15 alunos ou ex-alunos a trabalhar! E que todos os anos, praticamente, “(...) Nós precisamos (...)”, até mesmo durante o ano, quando (...) "Precisamos de mais dois elementos... vocês o que é que têm, o que têm neste momento, o que não têm (...)”. Quer dizer, já são alguns sítios que são mais ou menos certos e que nos garantem que eles desenvolvem um trabalho positivo em termos de estágio e há outros que vão surgindo, um contacto qualquer de uma empresa, "... Olhe, necessitava de um quadro assim, assim..." Então na altura de estágio, da data x a x, nós temos a possibilidade de efectuar este estágio e é um momento que pode ser um momento importante para... quer para o aluno verificar se se adapta ou não àquela situação profissional, e o contrário, se a empresa verifica que o elemento corresponde às necessidades que tem naquele momento. Em termos de estágio as coisas têm funcionado um bocado desta forma. (Leonardo, coordenador de curso da Escola Profissional Valdéon)

Os estágios curriculares (e profissionais) constituem, assim, frequentemente, situações em que as escolas proporcionam condições fa- 
Novas instituições e processos educativos: a educação e o modo...

voráveis para que as entidades empregadoras diminuam os riscos e custos associados à selecção e ao recrutamento de mão-de-obra. Colocando os estudantes com base numa primeira triagem da responsabilidade do estabelecimento de ensino e possibilitando a experiência e avaliação do candidato ao longo de várias semanas, tais dispositivos parecem constituir uma oportunidade portadora de benefícios não negligenciáveis por parte das instituições envolvidas. As escolas assumem assim um papel de prestadoras de serviços cujo sucesso no esforço de captação de ofertas de emprego depende das estratégias de gestão de recursos humanos das empresas.

Mesmo quando é escassa a disponibilidade de postos de trabalho numa dada área ou num determinado sector de actividade, a realização de estágios curriculares objectiva constituir uma forma de afirmação e promoção dos candidatos e da escola, como potencial fornecedora de mão-de-obra adequadamente socializada e qualificada para o trabalho.

A presença anual de dezenas de jovens num grande número de instituiçôes durante várias semanas permite alimentar um leque muito alargado de contactos que pode chegar a representar em alguns casos a principal via de inserção profissional dos formandos.

Mas nem sempre tais diligências são bem-sucedidas: quando a oferta de emprego aumenta e/ou as condições de contratação não chegam a ser satisfatórias para os candidatos, estes optam por inserçōes alternativas àquelas proporcionadas na sequência dos estágios curriculares. Do mesmo modo, quando a oferta de emprego é escassa ou inexistente, a disponibilidade das instituições para proporcionar estágios, a solicitação e valorização do trabalho realizado pelos alunos raramente se traduzem em oportunidades de inserção profissional. Nessas condiçôes, o esforço das escolas orienta-se no sentido de promover iniciativas que evidenciem a relevância das formações que oferecem junto de potenciais empregadores, buscando cativar, em benefício dos seus alunos, oportunidades e postos de trabalho que possam vir a ser colocados à disposição.

Há cursos onde haverá mais dificuldades, do que outros, por exemplo o curso de Comunicação creio eu que tem mais dificuldade, portanto aí vamos ter necessidade talvez de conhecer... Vi um carro com uma determinada empresa, tomei nota: "Deixa ver aqui há uma empresa que é das Artes Gráficas". 
Então é preciso visitar a empresa, ver o que lá estão a fazer; por isso uma das ideias que eu tenho em mente é no próximo ano ir falar mais com empresas, estabelecer uma relação familiar, porque é importante para o próprio... até por exemplo convidar as empresas a assistirem, os empresários a assistirem às Provas de Aptidão Profissional. Porque aqui podem ver as pessoas que saem, não é? Porque a Prova de Aptidão Profissional é um momento em que se podem ver as capacidades humanas de comunicação, de defesa de um projecto, e os empresários, naturalmente, podem encontrar aqui um momento propício para seleccionar um quadro... (Luís, director pedagógico da Escola Profissional Valdéon)

No caso em estudo, as duas escolas perfilham perspectivas e desenvolvem práticas bastante distintas no que toca à organização de estágios curriculares: a Escola Profissional Valdéon integra convictamente essa componente da formação no segundo e terceiro anos dos cursos ao longo de cerca de cinco semanas; a Escola Profissional Tresviso desvaloriza fortemente as potencialidades formativas de tal prática, promovendo a inserção dos alunos em contextos e actividades de trabalho reais apenas no curso de Técnico de Gestão Autárquica, que significativamente é aquele no qual se verificam maiores dificuldades na inserção profissional dos formandos.

Em qualquer dos casos, uma grande soma de energia é dispensada no trabalho de envolvimento de empresas e outras instituiçôes empregadoras em actividades e iniciativas com grande carga simbólica e valor cerimonial que visam quer a apresentar as facetas mais brilhantes da escola, quer a reafirmar o compromisso desta com aqueles a quem atribuem o protagonismo de seus parceiros privilegiados.

(...) Associação Comercial e Industrial (...) Estamos em fase grande de negociações com eles. Vêm sempre às nossas actividades, estão sempre presentes. (...) Prova de Aptidão, entrega de diplomas, as festas, colóquios, conferências... quando desenvolvem actividades, nós normalmente, muitas vezes as nossas alunas do curso de Secretariado vão secretariar as acções que eles desenvolvem. (Bento, director da Escola Profissional Tresviso)

Por último, as escolas desenvolvem ainda um outro tipo de práticas, com carácter mais ou menos sistemático e formal, que as constituem como centros, de maior ou menor envergadura, de recepção, ajustamento e encaminhamento de ofertas e pedidos de emprego. Quer por meio da integração de Unidades de Inserção na Vida Activa, 
Novas instituições e processos educativos: a educação e o modo...

no caso da Escola Profissional Tresviso, quer por força do estabelecimento de um serviço interno menos formalizado, essas instituições acolhem, e procuram constituir-se como instâncias de intermediação entre, a oferta e a procura de empregos susceptíveis de beneficiar a inserção profissional dos seus alunos.

Por exemplo: nós recebemos aqui um contacto de uma empresa: "Preciso de um técnico disto ou daquilo"; e nós sabemos se está colocado ou não está colocado, quem neste momento está a tratar é o coordenador de curso, conhece todos os alunos... Inicialmente funcionou dentro de uma Unidade de Inserção na Vida Activa, que era o projecto aprovado pelo Centro de Emprego, mas isto tem uma duração, normalmente, de três anos e depois extinguese, mas nós continuamos com o serviço. Fizemos um reajustamento, este serviço continua através de cada coordenador, se me pedem um técnico de electrónica eu remeto ou falo com o coordenador de electrónica para que ele faça o contacto. Está a haver aumento de contactos de empresas conosco a pedirnos alunos... Às vezes indicamos dois que vão a uma entrevista. Há cursos onde, normalmente, são todos colocados. (Luís, director pedagógico da Escola Profissional Valdéon)

\subsubsection{As escolas e a mediação da transição profissional: compromissos limitados}

A obrigação ou pressão, social e mesmo administrativamente reforçada, que recai sobre as escolas, de diligenciar a inserção profissional dos estudantes adoptando procedimentos e estabelecendo ligações e vias institucionais adequadas para o efeito, confere-lhes dimensões de actuação como entidades mediadoras da transição profissional que intervêm de modo específico para a "colocação [dos seus alunos] em trabalho". As escolas tendem assim a tomar por sua conta uma selecção individualizada e personalizada dos candidatos aos postos de trabalho colocados à disposição pelas empresas, procurando, com maior ou menor empenhamento, realizar um compromisso entre as solicitações e condiçôes dos empregadores e aquilo que vêm como os interesses da instituição e dos seus alunos.

A observação, o acompanhamento e o estudo por nós realizado - pese embora o seu carácter singular e consequentemente as limitações inerentes ao significado assumido pelas informações recolhidas sugerem, como foi referido, que, na qualidade de entidades mediadoras da transição profissional, as escolas, por meio dos seus responsáveis, 
colaboram com as empresas levando a cabo uma selecção individualizada e personalizada dos candidatos aos empregos, utilizando critérios que derivam de leituras particulares, e nem sempre consistentes, quer das solicitações das empresas, quer dos interesses dos alunos, frequentemente associando tais critérios a avaliações e classificações de matriz escolar quanto às características desses alunos. Tais actuaçôes dos responsáveis das escolas contribuem para constituir um contingente permanentemente renovado de candidatos a trabalhadores alocáveis a determinados segmentos do mercado de emprego (e de desemprego), que assim são distribuídos, canalizados ou mesmo estratificados segundo critérios relacionados com as suas características individuais e qualidades pessoais. Actuando, nesta medida, como "auxiliar externalizado das funçôes de recrutamento da empresa", procurando "fornecer-lhe o pessoal mais performante possível" as escolas contribuem para "a categorização de mão-de-obra" e para "o reforço da selectividade do mercado de emprego", sublinhados, entre outros autores, por Meyer (1998, p. 350, 353) e Rose (1996, p. 64).

Em contrapartida, alguns dos processos referidos parecem congruentes com a hipótese de que seria possível identificar hoje uma tendência crescente parar a "gestão 'individualizada' da força de trabalho" (em termos de formação, progressão na carreira, remuneração), de que a relação actual dos jovens com o trabalho (emprego), exigindo-lhes "comprometer-se num processo de inserção" em que avulta a indispensável "construção e demonstração de 'empregabilidade", constituiria uma das manifestações (Charlot \& Glasman, 1998a, p. 23, 20, 22; cf. também Castells, 1996, p. 264-272).

Ainda que o nosso estudo não seja orientado para proporcionar qualquer informação acerca das características dos postos de trabalho e empregos colocados à disposição dos candidatos provenientes das escolas estudadas, alguns indícios apontam no sentido de não raro se tratar de lugares sujeitos a grande rotação (e precariedade) e muito provavelmente pouco definidos e defendidos em termos dos diplomas e das qualificaçôes exigidos e reconhecidos, e dos direitos a que esses candidatos podem dar acesso. Uma tal afirmação é-nos sugerida, entre outros elementos que convergem no mesmo sentido, pela regularidade com que nos foi referido o facto, que também testemunhámos, de os empregadores considerarem irrelevante, para os postos e contratos de trabalho a que os alunos acedem, que estes concluam ou não o curso. Este constitui aliás, em alguns casos, um motivo de forte preocupação, formu- 
Novas instituições e processos educativos: a educação e o modo...

lada por directores de várias das escolas, que evocaram situações por eles descritas como de aliciamento dos jovens para empregos, na fase final dos cursos, objectivamente (e, segundo os mesmos responsáveis, não inocentemente por parte dos empregadores) desencorajando a conclusão e certificação desses cursos.

Em congruência com o que evidenciamos, num artigo intitulado "Qualificação profissional e desqualificação social na construção civil", Pinto \& Queiroz sublinham a incidência deste "processo contraditório de avaliação social de saberes e títulos” pelo qual, em face da relativa autonomização do sistema de ensino nas nossas sociedades, muito frequentemente os empregadores tendem a contestar ou ignorar o valor da formação sancionada pelos diplomas:

Assumir a importância da escolarização, nomeadamente a que se efectua por meio das fileiras técnicas e profissionais, resistindo ao mesmo tempo a reconhecer formalmente as qualificações que ela efectivamente confere, constitui, pois, uma das vias de contenção dos salários e das reivindicações em torno dos conteúdos e das condiçōes de trabalho, não sem assegurar ainda a flexibilização da mão-de-obra em termos de recrutamento e de promoção. (Pinto \& Queiroz, 1996, p. 46)

Apoiado nos estudos realizados desde o início dos anos de 1980, Rose tem vindo a argumentar que a organização da transição profissional promovida pelas políticas de emprego, formação e educação nos últimos anos se caracteriza por: "O papel crescente das empresas na formação, a desarticulação entre a actividade profissional e os recursos dos indivíduos, a precariedade crescente dos estatutos e dos estados, o papel essencial das instâncias de regulaçãao estatais ou intermediárias, a instabilidade dos tempos e a interpenetração das actividades de trabalho e de não-trabalho ('hors-travail'), o dualismo reforçado". Nesta medida, segundo o mesmo autor, tais fenómenos "prefiguram talvez os contornos de um novo salariato em curso de emergência" (Rose, 1996, p. 78, 63).

\subsubsection{No reino do informal: ligaçôes orgânicas e funcionais entre as escolas e as empresas \\ Um outro tipo de práticas que visa a favorecer a inserção pro- fissional dos alunos passa pela integração na sua formação de conteú- dos específicos relacionados com a aquisição e o treino de saberes e}


habilidades, nomeadamente de cariz técnico e prático, imediatamente mobilizáveis para a realização de tarefas inerentes a desempenhos profissionais em unidades e processos produtivos locais.

Inclusivamente, a Papelaco põe aqui as máquinas que a gente queira para eles aprenderem a montar e a desmontar e para ganharem prática, para saberem trabalhar a parte técnica. (Bento, director da Escola Profissional Tresviso)

Nestas condições, as relações entre a escola e algumas empresas assumem uma natureza e intensidade particulares que se aproximam de ligações (quase) orgânicas e funcionais - sem perderem o seu carácter informal - a todos os títulos singulares. Em certa medida, a escola assume valências que a configuram - de modo difuso - como uma extensão dessas empresas no domínio da formação de mão-de-obra especialmente qualificada que, em consequência, é preferencialmente recrutada dados os benefícios visíveis que, de tais situações, essas empresas parecem retirar. Nesta medida se vislumbra a constituição de uma modalidade de relação entre a formação e o emprego (e entre os sistemas educativo e produtivo) que releva, como sugere Rose, mais da interpenetração e da "aproximação (no tempo, no espaço e nos conteúdos) dos momentos de preparação e de utilização de mão-de-obra” do que da adequação. Essas relaçōes constituir-se-iam com base em "processos sociais combinando formação, alocação e utilização da mão-de-obra”, verificando ainda uma crescente intervenção e influência das empresas em domínios como o da educação (Rose, 1984, p. 186; 1996, p. 69).

Esta breve análise dos dispositivos mobilizados para a inserção profissional dos jovens nas escolas profissionais estudadas sugere, como hipótese plausível, que a relação salarial em que muitos deles vêm a ser, por esta via, envolvidos caracteriza-se pela diluição de vínculos entre as qualificações mobilizáveis no exercício do trabalho, aquelas formalmente certificadas e o reconhecimento de umas e outras por meio do salário e de outros benefícios e direitos laborais, bem como pela precariedade e pela individualização dos contratos de trabalho obtidos. Em contrapartida, a análise realizada, que aponta para a constituição das escolas profissionais como parte do dispositivo de transição profissional no nosso país, assumindo a gestão da inserção dos seus alunos no emprego, é consistente com as propostas interpretativas que identificam a formação de uma relação de imbricação - ainda com contornos instáveis e 
Novas instituições e processos educativos: a educação e o modo...

poucos claros - entre (segmentos de) sistemas educativo, produtivo e de emprego. Nessa medida, as alterações à relação salarial fordista parecem suscitar a emergência de uma nova dimensão da participação da educação na regulação social: o envolvimento na organização da transição profissional, mediante processos que combinam a formação, a alocação e a utilização da força de trabalho. Esta constituiria ainda uma das componentes do processo de recontextualização da educação em face do mundo e das instituições produtivos e de trabalho. ${ }^{16}$

\section{3. $\mathrm{O}$ modo de regulação em gestação: novas instituições e processos educativos}

A agenda política nacional para a educação, desenvolvida em Portugal entre 1988 e 1993, incluiu alguns vectores que pudemos salientar por intermédio da análise do subsistema de escolas profissionais; a estruturação dessa agenda por processos globais foi evidenciada por meio da sinalização de modalidades de intervenção do Estado, no contexto desta inovação, que condensamos sob as fórmulas de Estado de competição e Estado-articulador e que corporizam alterações em curso no modo de regulação. Assim, sublinhamos, como linhas de força daquela agenda política concretizadas pela inovação em análise, a ampliação e fragilização da cidadania educativa, o ensaio de novas modalidades de provisão de serviços educativos e a recontextualização da educação em face do mundo e das instituições produtivos e de trabalho - em qualquer destes domínios da acção política estão em causa o ensaio de novas instituiçóes e de novos processos educativos.

A análise que construímos com base nos testemunhos recolhidos sobre orientações e práticas de gestão da inserção profissional dos jovens no contexto das Escolas Profissionais Tresviso e Valdéon dá visibilidade ao envolvimento dessas instituições na organização da transição profissional, permitindo sugerir estarmos perante uma relação entre os sistemas educativo, produtivo e de emprego que releva já não da adequação mas da imbricação entre espaços e momentos de formação, alocação e utilização da força de trabalho.

O desenvolvimento de novas instituiçôes e de novos processos educativos, corporizando a já salientada emergência de novas dimensões e/ou configurações da participação da educação na regulação social, testemunhado pelo estudo do subsistema de escolas profissionais em 


\title{
Portugal permite, como procuramos defender, esboçar alguns dos con- tornos e percursos pelos quais um novo modo de regulação pode vir a tomar forma.
}

\author{
Recebido em fevereiro de 2004 e aprovado em junho de 2004.
}

\section{Notas}

1. Boyer define regime de acumulação como o "conjunto das regularidades que permitem uma acumulação mais ou menos coerente do capital, isto é, que amortecem e esbatem no tempo os desequilíbrios gerados constantemente pelo próprio processo de formação do capital", definindo-se pelas seguintes características: (i) "um tipo de organização da produção intra e inter empresas (...)"; (ii) "um horizonte temporal que serve de referência às decisões de investimento dos empresários (...)"; (iii) "uma repartição dos rendimentos entre salários, lucros e impostos (...)" ; (iv) "o volume e a composição de procura efectiva (...)"; (v) "as relações entre os modos de produção pré-capitalistas e o capitalismo" (cf. Boyer, 1994, p. 122-123).

2. As organizações regionais mais importantes são hoje a União Europeia (UE), a Associação Norte-Americana de Comércio Livre (NAFTA) e o Fórum de Cooperação Económica da ÁsiaPacífico (APEC); entre as organizações internacionais mais relevantes contam-se a Organização das Nações Unidas (ONU), o Banco Mundial (BM), o Fundo Monetário Internacional (FMI), a Organização Mundial do Comércio (OMC), a Organização para Cooperação e Desenvolvimento Económico (OCDE).

3. Nóvoa, num trabalho que constitui o primeiro estudo que conhecemos em Portugal sobre a intervenção da Comunidade/União Europeia no domínio da educação, chama a atenção para a "longa lista de documentos. que definem orientaçôes ao mesmo tempo em que constroem uma linguagem para falar da educação na Europa", sublinhando a importância dos discursos para a definição e sustentação das políticas nacionais e comunitárias e defendendo consequentemente a necessidade da sua análise (Nóvoa, 1998, p. 97-111, grifos no original).

4. Este conceito, desenvolvido pela Escola da Regulação francesa, releva que a trama de instituiçóes que favorecem a congruência dos comportamentos individuais e colectivos e medeiam os conflitos sociais chega a produzir as condições para a estabilização (sempre temporária e dinâmica, ainda que prolongada) de um dado regime de acumulação (cf. Boyer, 1987, p. 54-55; 1997, p. 3; Aglietta, 1997, p. 412, 429; cf. ainda Antunes, 1998, p. 30-32).

5. Para uma discussão mais aprofundada desta problemática consultar Antunes (2003b, p. 82-91); Afonso (2001) analisa algumas importantes implicações para as políticas educativas decorrentes da redefinição do papel do Estado.

6. A perspectiva de uma agenda globalmente estruturada para a educação admite, com base em estudos de economia política, que os Estados-nação se confrontam com "um conjunto sistemático de questôes", colocadas quer pelos processos de globalização (económicos, políticos, culturais), quer pela situação desses mesmos Estados no contexto internacional que condiciona a sua relação com esses processos (cf. Dale, 2000b, p. 428). O argumento principal da perspectiva de uma agenda globalmente estruturada para a educação é susten-

Educ. Soc., Campinas, vol. 25, n. 87, p. 481-511, maio/ago. 2004

Disponível em <http://www.cedes.unicamp.br> 
Novas instituições e processos educativos: a educação e o modo...

tado pela análise de que o modo como aqueles problemas se apresentam e a prioridade relativa que lhes é atribuída são crescentemente modelados pelos constrangimentos e pelas pressōes de relações globais (sobretudo económico-políticas), dispondo os Estados de um leque diminuído de opções quanto à orientação das suas políticas. Tal não implica que a actuação do Estado seja determinada pelo contexto económico-político global/regional, mas as orientaçôes adoptadas e os processos sociais implementados serão o resultado da interacção complexa entre a percepção/interpretação e formulação daqueles problemas pelos actores do Estado, da sociedade civil e da economia e o leque de respostas e soluçóes disponibilizáveis por intermédio das instituiçōes existentes ou possíveis a partir dos recursos políticos, económicos e culturais mobilizáveis no contexto nacional.

7. Nessa data o ensino básico obrigatório compreendia apenas seis anos e o ensino secundário abrangia os dois ciclos seguintes. A Reforma do Sistema Educativo dos anos de 1980 traduziu-se, neste domínio, pelo prolongamento da escolaridade obrigatória para nove anos e a circunscrição do ensino secundário aos $10^{\circ}, 11^{\circ}$ e $12^{\circ}$ anos.

8. São contemporâneas da implementação de um subsistema de escolas profissionais, em 1989, as seguintes medidas: abertura de cursos de Aprendizagem em alternância, concedendo um certificado de qualificação profissional de nível III com equivalência ao $12^{\circ}$ ano (criados em 1988, entram em funcionamento apenas em 1991); a reforma curricular do ensino secundário regular, em 1989, com entrada em vigor a partir de 1990/1991, instaurando Cursos Predominantemente Orientados para o Prosseguimento de Estudos (Cursos Gerais) e Cursos Predominantemente Orientados para o Ingresso na Vida Activa (Cursos Tecnológicos). Desse modo, o ensino/formação de nível secundário está hoje (2003) organizado em quatro segmentos. Diferentes análises dessas medidas podem ser encontradas em Stoer, Stoleroff \& Correia (1990), Grácio (1998a e 1998b), Pedroso (1998), Resende \& Vieira (1998), Gomes (1999), Antunes (2000a).

9. Para uma mais ampla compreensão desse processo consultar Afonso (1998), que desenvolve a análise mais abrangente e aprofundada que conhecemos sobre a Reforma do Sistema Educativo Português nos anos de 1980 em Portugal. O estudo apresentado por Lima (1998) sobre "a administração do sistema educativo e das escolas" constitui igualmente uma referência nessa área.

10. Deve ser salientado que, nessa época, em Portugal, de uma forma não verificável em outros países europeus e ocidentalizados, convergiram múltiplas pressões para a expansão dos serviços educativos em todos os níveis do sistema, desde a educação de infância ao ensino superior (cf. Vilarinho, 2000; Afonso, 1998; Seixas, 2001).

11. Essa análise do(s) modelo(s) de governação do subsistema de escolas profissionais incidirá mais demoradamente no período compreendido entre 1989 e 1998 . Na sequência de perturbações e instabilidades diversas, no que respeita ao financiamento dessas escolas, foi realizada, em 1996, uma avaliação do subsistema de escolas profissionais (cf. Silva, Silva \& Fonseca, 1997) e, posteriormente, estabelecido um novo "regime de criação, organização e funcionamento de escolas e cursos profissionais no âmbito do ensino não-superior" por intermédio do Decreto-lei n. 4/98 de 8 de janeiro. Este diploma introduziu alteraçôes diversas cujo significado e consequências não poderemos neste momento explorar. Para uma análise mais detalhada dos desenvolvimentos verificados na governação do subsistema de escolas profissionais ao longo destes 14 anos, consultar Antunes (2000b, 2001, 2003a).

12. Para Roger Dale, regulação designa, nesse contexto, as actividades de controlo, isto é, de definição do enquadramento para o fornecimento dos serviços educativos que o Estado assume por intermédio de políticas e sanções legais (cf. Dale, 1997, p. 277). Parecendo 
consistir numa atribuição última deste, é possível, no entanto, admitir que outras instâncias ou entidades desempenhem igualmente aqui um papel em áreas definidas pelo, e porventura por delegação do, Estado.

13. A configuração desse subsistema criou, desde o primeiro momento, condições para a constituição de um quase-mercado (cf. Le Grand \& Bartlett, 1993a, p. 3, 10), dadas a separação e a alocação das diversas actividades de governação verificadas. No entanto, os dados de que dispomos sugerem que, pelo menos até 1998, o tipo de envolvimento do Estado com a criação e sustentação de cada escola, entre outros aspectos, contribuiu para atenuar possíveis desenvolvimentos naquele sentido. Pensamos que o novo "regime de criação, organização e funcionamento de escolas e cursos profissionais no âmbito do ensino não-superior”, estabelecido por intermédio do Decreto-lei n. 4/98 de 8 de janeiro, conduziu à clarificação da situação; dessa forma, sem ambiguidades, o Estado passou a, em certas condiçôes, adquirir determinados serviços educativos proporcionados pelas escolas, declinando, assim, aquele tácito compromisso com a sustentação financeira desse subsistema quase exclusivamente privado (o que pode não ter alterado a situação de, agora na qualidade de "cliente", permanecer como o seu principal financiador). Neste sentido, terão sido reforçadas as condiçôes que, conforme argumentámos, potenciavam já o estabelecimento de um quase-mercado neste sector do sistema de ensino. Deve ser notado que esta evolução alterou significativamente o quadro da governação desse subsistema. Em contrapartida, as propostas conhecidas para o financiamento após a conclusão do III Quadro Comunitário de Apoio, em 2006, e que estão a ser experimentadas já neste ano (2003/2004) nas escolas profissionais da região de Lisboa e Vale do Tejo, sugerem que a institucionalização deste quase-mercado será consolidada, agora sob novos moldes; pode verificar-se ainda o reforço de mecanismos de mercado, já que é susceptível de vir a adquirir um maior significado a participação do financiamento privado pelos próprios estudantes, por meio de propinas (cf. Antunes, 2003a).

14. A pesquisa de terreno em que se baseia a análise a seguir apresentada desenvolveu-se, entre junho de 1999 e julho de 2000, como um estudo de caso incidente em duas unidades de observação - a Escola Profissional Valdéon e a Escola Profissional Tresviso; a recolha de informações assentou na realização de 21 entrevistas semi-estruturadas com responsáveis da direcção, da gestão pedagógica, docentes, estudantes; realizámos também a observação de várias horas de aulas e de sessões de organização e acompanhamentos de estágios curriculares. A discussão que vamos iniciar está, dados os objectivos deste texto, forçosamente amputada de elementos importantes para a documentação e sustentação das interpretaçóes propostas; estas se encontram mais detalhadamente enunciadas e sublinhadas pela apresentação de dados empíricos em Antunes (2003b e 2002).

15. Roger Dale define o mandato como as concepções predominantes acerca do que é legítimo e desejável alcançar por meio do sistema educativo (cf. Dale, 1988 e 1989).

16. Esta expressão é inspirada em Moore (1987) e pretende sintetizar um conjunto de fenómenos que analisámos mais demoradamente em Antunes (1999, 2003b).

\section{Referências bibliográficas}

\section{AFONSO, A.J. Políticas educativas e avaliação educacional: para uma análise sociológica da reforma educativa em Portugal (1985-1995). Braga: Universidade do Minho, 1998.}

Educ. Soc., Campinas, vol. 25, n. 87, p. 481-511, maio/ago. 2004

Disponível em <http://www.cedes.unicamp.br> 
Novas instituições e processos educativos: a educação e o modo...

AFONSO, A.J. A redefinição do papel do Estado e as políticas educativas: elementos para pensar a transição. Sociologia: problemas e práticas, Portugal, n. 37, p. 33-48, 2001.

AGLIETTA, M. Régulation et crises du capitalisme. Paris: Odile Jacob, 1997.

ALVES, J.M. Modos de organização, direcção e gestão das escolas profissionais: um estudo de quatro situações. Porto: Porto, 1996.

ANTUNES, F. Politicas educativas para Portugal anos 80/90: o debate acerca do ensino profissional na escola pública. Lisboa: Instituto de Inovação Educacional, 1998.

ANTUNES, F. Orientações e mudanças para a educação no contexto comunitário: alguns elementos e breves anotaçôes. In: CONGRESSO da Sociedade Portuguesa de Ciências da Educação "Investigar e formar em educação”, 4., Porto, 1999. Actas do... Porto: SPCE, 1999. v.1. p. 399-412.

ANTUNES, F. Novas instituições e processos educativos: a reforma portuguesa do ensino secundário no contexto comunitário (19881996). In: Pacheco, J.A. (Org.). Políticas educativas: o neoliberalismo em educação. Porto: Porto, 2000a. p. 109-134.

ANTUNES, F. Novas diferenciações e formas de governação em educação: o processo de criação das escolas profissionais em Portugal. Revista Brasileira de Política e Administração da Educação, Porto Alegre, v. 16, n. 1, p. 31-45, 2000 b.

ANTUNES, F. Os locais das escolas profissionais: novos papéis para o Estado e a europeização das políticas educativas. In: STOER, S.R.; Cortesão, L.; Correia, J.A. (Org.). Transnacionalização da educação: da crise da educação à "educação" da crise. Porto: Afrontamento, 2001. p. 163-208.

ANTUNES, F. Apertando laços entre a educação, a produção e o emprego?: as escolas profissionais e a gestão da inserção profissional dos jovens. In: CONGRESSO Luso-Brasileiro de Política e Administração da Educação, 2. Braga, 2001. Investigação, formação e práticas. Braga: Centro de Investigação em Educação; IEP; Universidade do Minho, 2002. p. 671-682 (CD-ROM). 
ANTUNES, F. Novas modalidades de provisão da educação: o subsistema de escolas profissionais em Portugal. Comunicação apresentada ao 2 . Congresso do Forum Português de Administração Educacional "A escola entre o Estado e o mercado: o público e o privado na regulação da educação". Lisboa, maio 2003a (texto policopiado)

ANTUNES, F. Políticas educativas nacionais e globalização: novas instituições e processos educativos; o subsistema de escolas profissionais em Portugal (1987-1998). 2003. Tese (Doutorado) - Instituto de Educação e Psicologia, Universidade do Minho, Braga.

AZEVEDO, J. Educação tecnológica nos anos noventa. Rio Tinto: Asa, 1991. BENKO, G.; LIPIETZ, A. (Org.). As regiōes ganhadoras: distritos e redes, os novos paradigmas da geografia económica. Oeiras: Celta, 1994.

BOYER, R. La théorie de la régulation: une analyse critique. Paris: La Découverte, 1987.

BOYER, R. As alternativas ao fordismo dos anos 80 ao século XXI. In: BenKo, G.; Lipietz, A. (Org.). As regiōes ganhadoras: distritos e redes, os novos paradigmas da geografia económica. Oeiras: Celta, 1994. p. 121-142.

BOYER, R. How does a new production system emerge? In: BOYER, R.; Durand, J.-P. After fordism. London: Macmillan, 1997. p. 1-63.

BOYER, R.; DURAND, J.-P. After fordism. London: Macmillan, 1997.

CALAN, D.; CARLIER, N.; VINOKUR, A. Qui veut l'insertion? In: Charlot, B.; Glasman, D. (Dir.). Les jeunes, l'insertion, l'emploi. Paris: PUF, 1998. p. 61-74.

CASTELLS, M. The rise of the network society. Oxford: Blackwell, 1996. (The information age, v.1)

CASTELLS, M. The power of identity. Oxford: Blackwell, 1997. (The information age, v.2)

CASTELLS, M. End of millennium. Oxford: Blackwell, 1998. (The information age, v.3)

CERNY, P.G. The changing architecture of politics: structure, agency and the future of the State. London: Sage, 1990. 
Novas instituições e processos educativos: a educação e o modo...

CHARLOT, B.; GLASMAN, D. Introduction. In: CHARLot, B.; GLASMAN, D. (Dir.). Les jeunes, l'insertion, l'emploi. Paris: PUf, 1998a. p. 11-26.

CHARLOT, B.; GLASMAN, D. (Dir.). Les jeunes, l'insertion, l'emploi. Paris: PUF, 1998b.

DALE, R. A educação e o Estado capitalista: contribuições e contradições. Educação e Realidade, Porto Alegre, v. 13, n.1, p. 17-37, 1988.

DALE, R. The State and education policy. Milton Keynes: Open University, 1989.

DALE, R. Locating "the family and education" in the year of the family. Keynote address to Australia and New Zealand Comparative Education Society Conference, Melbourne, dec. 1994 (texto policopiado).

DALE, R. The State and the governance of education: an analysis of the restructuring of the State-education relationship. In: Halsey, A.H.; Lauder, H.; Brown, P.; Wells, A.S. (Org.). Education: culture, economy and society. Nova York: Oxford University, 1997. p. 273-282.

DALE, R. Globalization: a new world for comparative education? In: SCHriewer, J. (Ed.). Discourse formation in comparative education. Berlin: Peter Lang, 2000a. p. 87-109.

DALE, R. Globalization and education: demonstrating a "common world educational culture" or locating a "globally structured educational agenda”? Educational Theory, Urbana, v. 50, n.4, p. 427-448, 2000 b.

DALE, R.; OZGA, J. Introducing education policy: principles and perspectives. In: E333 Policy Making in Education: a third level course. Milton Keynes: Open University, 1991.

DALE, R.; ROBERTSON, S. Regional organizations as a medium of globalization of education. Comunicação apresentada ao workshop Reflecting Globalization Effects on National Education Policy: the perspective from East Asia, City University of Hong Kong, sept. 2000 (texto policopiado).

DUPAQUIER, M.; FOURCADE, B.; GADREY, N.; PAUL, J.-J.; ROSE, J. L'insertion professionnelle. In: TANGUY, L. (Dir.). L'introuvable relation formation-emploi: un état des recherches en France. Paris: La Documentation Française, 1986. p. 35-88. 
ESTEVES, A.J. Jovens e idosos: família, escola e trabalho. Porto: Afrontamento, 1994.

GOMES, R. 25 anos depois: expansão e crise da escola de massas em Portugal. Educação, Sociedade \& Culturas, Porto, n. 11, p. 133-164, 1999.

GRÁCIO, S. Ensinos técnicos e política em Portugal, 1910-1990. Lisboa: Instituto Piaget, 1998a.

GRÁCIO, S. Ensino privado em Portugal: contributos para uma discussão. Sociologia: problemas e práticas, Portugal, n. 27, p. 129-153, 1998 b.

HALSEY, A.H.; LAUDER, H.; BROWN, P.; WELLS, A.S. (Org.). Education: culture, economy and society. Nova York: Oxford University, 1997.

LE GRAND, J.; BARTLETT, W. Introduction. In: LE GRAND, J.; BARTLETT, W. (Org.). Quasi markets and social policy. London: Macmillan, 1993a. p. $1-12$.

LE GRAND, J.; BARTLETT, W. (Org.). Quasi markets and social policy. London: Macmillan, 1993b.

LIMA, L.C. A administração do sistema educativo e das escolas (1986/1996). In: PORTUGAL. Ministerio da Educação. A evolução do sistema educativo e o PRODEP; estudos temáticos, v.1. Lisboa: Ministério da Educação; DAPP, 1998. p. 15-96.

MEYER, J.-L. Intermédiaires de l'emploi et marché du travail. Sociologie du Travail, Paris, v.40, n. 3, p. 345-364, 1998.

MOORE, R. Education and the ideology of prodution. British Journal of Sociology of Education, Oxforshire, v. 8, n. 2, p. 227-242, 1987.

NÓVOA, A. Histoire e comparaison: essais sur l'éducation. Lisboa: Educa, 1998.

PACHECO, J.A. (Org.). Politicas educativas: o neoliberalismo em educação. Porto: Porto, 2000.

PEDROSO, P. Formação e desenvolvimento rural. Oeiras: Celta, 1998.

PINTO, J.M.; QUEIROZ, M.C. Qualificação profissional e desqualificação social na construção civil. Cadernos de Ciências Sociais, n. 15/16, p. 41-85, 1996. 
Novas instituições e processos educativos: a educação e o modo...

PORTUGAL. MINISTERIO DA EDUCAÇÃO. GABINETE DE ESTUDOS E PLANEAMENTO. PRODEP: Programa de Desenvolvimento Educativo para Portugal, 1990-1993; PRODEP com contribuição comunitária. Lisboa: GEP; ME, 1990.

RESENDE, J.M; VIEIRA, M.M. As encruzilhadas da escolarização secundária no limiar do séc. XXI. In: Fernandes, D.; Mendes, M.R. (Org.). O ensino secundário em debate; conferência internacional do Ensino Secundário - Projectar o Futuro: políticas, currículos, práticas. Lisboa: Ministério da Educação; Departamento do Ensino Secundário, 1998. p. 63-97.

ROSE, J. En Quête d'emploi. formation, chômage, emploi. Paris: Economica, 1984.

ROSE, J. L'organisation des transitions professionnelles entre socialisation, mobilisation et recomposition des rapports de travail et d'emploi. Sociologie du Travail, Paris, v. 38, n. 1, p. 63-79, 1996.

SANTOS, B.S. O Estado e a sociedade em Portugal (1974-1988). Porto: Afrontamento, 1990.

SANTOS, B.S. Reinventar a democracia. Lisboa: Fundação Mário Soares; Gradiva, 1998.

SANTOS, B.S. A reinvenção solidária e participativa do Estado. Coimbra: Centro de Estudos Sociais, 1999.

SANTOS, B.S. Os processos de globalização. In: SANTOS, B.S. (Org.). Globalização: fatalidade ou utopia? Porto: Afrontamento, 2001a. p. 31106.

SANTOS, B.S. (Org.). Globalização: fatalidade ou utopia? Porto: Afrontamento, 2001b.

SCHRIEWER, J. (Ed.). Discourse formation in comparative education. Berlin: Peter Lang, 2000.

SEIXAS, A.M. Políticas educativas para o ensino superior: a globalização neoliberal e a emergência de novas formas de regulação estatal. In: STOER, S.R.; CorTesão, L.; CorreiA, J.A. (Org.). Transnacionalização da educação: da crise da educação à "educação" da crise. Porto: Afrontamento, 2001. p. 209-238. 
SILVA, J.M.; SILVA, A.S.; FONSECA, J.M.P. Avaliação do sistema de escolas profissionais. Lisboa: Ministério da Educação, 1997.

STOER, S.R. Desocultando o voo das andorinhas: educação inter/ multicultural crítica como movimento social. In: STOER, S.R.; CORTESĀO, L.; CorreiA, J.A. (Org.). Transnacionalização da educação: da crise da educação à "educação" da crise. Porto: Afrontamento, 2001. p. 245-275.

STOER, S.R.; ARAÚJO, H. Escola e aprendizagem para o trabalho num pais da (semi)periferia europeia. Lisboa: Escher, 1992.

STOER, S.R.; CORTESÂO, L.; CORREIA, J.A. (Org.). Transnacionalização da educação: da crise da educação à "educação" da crise. Porto: Afrontamento, 2001.

STOER, S.R.; STOLEROFF, A.; CORREIA, J.A. O novo vocacionalismo na política educativa em Portugal e a reconstrução da lógica da acumulação. Revista Crítica de Ciências Sociais, Coimbra, n. 29, p. 11-53, 1990.

TANGUY, L. (Dir.). L'introuvable relation formation-emploi: un état des recherches en France. Paris: La Documentation Française, 1986.

VILARINHO, M.E. Políticas de educação pré-escolar em Portugal (19771997). Lisboa: Instituto de Inovação Educacional, 2000.

WALLERSTEIN, I. Culture as the ideological battleground of the modern world-system. In: Featherstone, M. (Org.). Global culture: nationalism, globalization and modernity. London: Sage, 1990. p. 31-55.

WALLERSTEIN, I. Unthinking social science: the limits of NineteenthCentury paradigms. Cambridge: Polity, 1991.

WALLERSTEIN, I. Mudança social?: a mudança é eterna; nada muda nunca. Revista Crítica de Ciências Sociais, Coimbra, n. 44, p. 3-23, 1995. 